\title{
Behavioural effects and supersensitivity in the rat following intranigral MPTP and MPP ${ }^{+}$administration
}

\author{
Klaus W. Lange \\ Laboratory of Psychobiology, Institute of Psychology, University of Dïsseldorf, Düsseldorf, F.R.G. \\ and University Department of Neurology, Institute of Psychiatry, London, U.K.
}

Received 2 October 1989, accepted 24 October 1989

\begin{abstract}
Unilateral intranigral injections of MPTP (1-methyl-4-phenyl-1,2,3,6-tetrahydropyridine) and $\mathrm{MPP}^{+}$(1-methyl-4phenylpyridine) were given to young rats and unilateral intranigral injections of MPTP were given to old rats. MPTP in old rats and $\mathrm{MPP}^{+}$in young rats induced ipsiversive circling for at least one week after injection and contraversive circling after the systemic administration of apomorphine; the number of D-2 receptors $\left(B_{\max }\right)$ in the striatum of the injected hemisphere increased compared with that of control rats. MPTP in young rats induced only short-lasting ipsiversive circling and no contraversive circling after apomorphine; the number of striatal D-2 receptors did not increase. These results suggest that the neurotoxicity of MPTP is age-dependent in the rat, and that MPTP has neurotoxic effects on the nigrostriatal dopaminergic system in old rats and induces dopamine receptor supersensitivity in the denervated striatum.
\end{abstract}

MPTP (1-methyl-4-phenyl-1,2,3,6-tetrahydropyridine); $\mathrm{MPP}^{+}$(1-methyl-4-phenylpyridine); Substantia nigra; Circling behaviour; Ageing; (Supersensitivity)

\section{Introduction}

Exposure of human subjects and non-human primates to 1-methyl-4-phenyl-1,2,3,6-tetrahydropyridine (MPTP) causes a Parkinsonian syndrome accompanied by destruction of dopamine-containing neurones in the substantia nigra pars compacta (SNC; see Langston, 1987). The brains of rodents, in particular those of rats, are much less sensitive to the neurotoxic effects of MPTP than the brains of primates are. The systemic administration of MPTP to rats failed to cause neurotoxicity (Chiueh et al., 1984), and the intranigral administration of MPTP to rats did not induce lasting damage to the dopaminergic nigral neurones (Chiueh et al., 1984; Bradbury et al., 1986) or lasting behavioural effects (Welzl and Lange, 1986). Studies on the mechanisms of MPTP toxic-

Correspondence to: K.W. Lange, Department of Neurology, Institute of Psychiatry, Denmark Hill, London SE5 8AF, U.K. ity have shown an important role of the enzyme monoamine oxidase B (MAO B), which oxidizes MPTP to 1-methyl-4-phenylpyridine $\left(\mathrm{MPP}^{+}\right)$; $\mathrm{MPP}^{+}$accumulates in dopaminergic neurones and appears to kill the cells by interfering with their energy metabolism (see Langston, 1987). The neurotoxicity of MPTP seems to be age-dependent. For example, MPTP produces severe damage in the substantia nigra and causes marked motor impairments in old mice whereas it has only minor effects in young mature mice (Gupta et al., 1986). The present study examined the behavioural effects of unilateral injections of MPTP and MPP ${ }^{+}$ into the SNC and the age dependence of MPTP neurotoxicity in the rat.

\section{Materials and methods}

Young adult (aged 4-5 months) and old (aged 22-24 months) male BD IX rats were used. Both 
young $(\mathrm{n}=8)$ and old $(\mathrm{n}=8)$ rats received a unilateral injection of $50 \mu \mathrm{g} / 1 \mu 1$ MPTP (Research Biochemicals Inc., Wayland, MA) into the SNC through cannulas. Young adult $(\mathrm{n}=8)$ and old $(\mathrm{n}=8)$ control rats received a saline solution which was equimolar to the MPTP solution. Another group of young rats $(n=8)$ was given unilateral intranigral injections of $4 \mu \mathrm{g} / 1 \mu 1 \mathrm{MPP}^{+}$iodide (Research Biochemicals Inc., Wayland, MA) and control animals $(n=8)$ received injections of an equimolar $\mathrm{NaI}$ solution. The stereotaxic coordinates for the intranigral injection corresponded to König and Klippel (1963) coordinates: A 2420, V -2.4 , L 1.6 .

The circling behaviour of all groups was recorded automatically with the animals in a square box $(0.5 \times 0.5 \mathrm{~m})$. Recordings were made for 30 min on the 1 st and 7 th day after the intranigral injection and on the 7th day for $30 \mathrm{~min}$ after the s.c. injection of apomorphine $(0.5 \mathrm{mg} / \mathrm{kg}$; Woelm Pharma, Eschwege, F.R.G.).

Ten days after the intranigral injection the rats were decapitated and their brains were rapidly removed onto ice. The striatum was dissected out and placed into ice-cold $50 \mathrm{mM}$ Tris- $\mathrm{HCl}$ buffer (pH 7.6). The specific binding of $\left[{ }^{3} \mathrm{H}\right]$ spiperone (18-19 $\mathrm{Ci} / \mathrm{mmol}$; concentrations between 0.1 and $1.0 \mathrm{nM}$; Amersham International, U.K.) in tissue homogenates of the striatum was determined by the method of Leysen et al. (1978); a final tissue suspension of 1 in $800 \mathrm{w} / \mathrm{v}$ in an incubation buffer containing $50 \mathrm{mM}$ Tris- $\mathrm{HCl}$ and $120 \mathrm{mM}$ $\mathrm{NaCl}$ ( $\mathrm{pH} 7.6$ ) was used. The striatum of the injected hemisphere and of the intact hemisphere of each rat was assayed separately. Non-specific binding of $\left[{ }^{3} \mathrm{H}\right]$ spiperone was defined by the incorporation of $10^{-5} \mathrm{M}( \pm$ )-sulpiride (Delagrange, Paris, France) in the incubation buffer. All determinations were carried out in triplicate. The number of binding sites $\left(\mathrm{B}_{\max }\right)$ and the apparent equilibrium constant $\left(\mathrm{K}_{\mathrm{d}}\right)$ were determined by Eadie-Hofstee analysis.

\section{Results}

The unilateral intranigral injection of MPTP induced strong ipsiversive circling (i.e. towards the side of injection) in both young adult and old rats on the 1st day after injection (see fig. 1). Seven days after the MPTP injection, spontaneous ipsiversive circling behaviour was still present in old rats whereas young adult rats did not circle preferentially in either direction. Young adult and old control rats injected with saline showed no asymmetry in their circling behaviour. Old rats that had received unilateral MPTP injections circled contraversively when injected with apomorphine 7 days after the injection; young rats did not show contraversive circling after the administration of apomorphine (see fig. 1). The unilateral intranigral injection of $\mathrm{MPP}^{+} \mathrm{I}$ produced ipsiversive circling on the 1 st and 7 th day after injection. The sys-

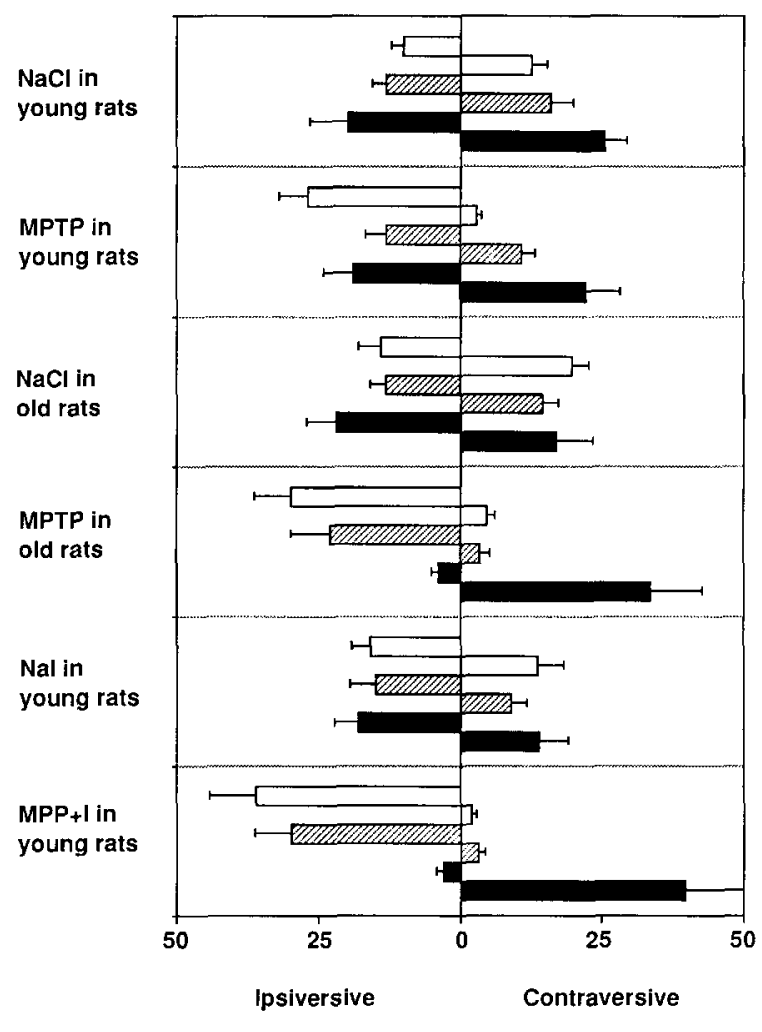

rotations per 30 minutes

Fig. 1. Ipsiversive and contraversive circling on day 1 (white bars) and day 7 (hatched bars) after unilateral injection of MPTP, $\mathrm{MPP}^{+} \mathrm{I}$ and control solutions into the substantia nigra pars compacta of young adult and old rats, and apomorphineinduced circling on day 7 after injection (black bars). Mean values \pm S.E. are shown. 
TABLE 1

Number $\left(B_{\max }\right)$ and affinity $\left(K_{d}\right)$ of D-2 receptors, identified by specific $\left[{ }^{3} H\right]$ spiperone binding, in the striatum of the injected and intact hemispheres on day 10 after unilateral intranigral injection of MPTP, MPP ${ }^{+}$and control solutions in young adult and old rats.

\begin{tabular}{|c|c|c|c|c|c|}
\hline \multirow[t]{2}{*}{ Treatment } & \multirow{2}{*}{$\begin{array}{l}\text { No. of } \\
\text { animals }\end{array}$} & \multicolumn{2}{|l|}{ Injected hemisphere } & \multicolumn{2}{|l|}{ Intact hemisphere } \\
\hline & & $\begin{array}{l}\mathrm{B}_{\max }(\mathrm{pmol} / \mathrm{g} \text { wet } \\
\text { weight of tissue) }\end{array}$ & $\overline{K_{d}}(n M)$ & $\begin{array}{l}\mathrm{B}_{\max }(\mathrm{pmol} / \mathrm{g} \text { wet } \\
\text { weight of tissue) }\end{array}$ & $\mathrm{K}_{\mathrm{d}}(\mathrm{nM})$ \\
\hline $\mathrm{NaCl}$ in young rats & 8 & $23.1 \pm 0.6$ & $0.18 \pm 0.01$ & $23.6 \pm 0.6$ & $0.16 \pm 0.01$ \\
\hline MPTP in young rats & 8 & $22.8 \pm 0.7$ & $0.18 \pm 0.01$ & $24.1 \pm 0.9$ & $0.18 \pm 0.01$ \\
\hline $\mathrm{NaCl}$ in old rats & 8 & $21.6 \pm 0.6$ & $0.14 \pm 0.01$ & $21.1 \pm 0.8$ & $0.16 \pm 0.01$ \\
\hline MPTP in old rats & 8 & $28.8 \pm 0.7^{a}$ & $0.15 \pm 0.01$ & $22.8 \pm 0.4$ & $0.14 \pm 0.01$ \\
\hline $\mathrm{NaI}$ in young rats & 8 & $22.1 \pm 0.6$ & $0.19 \pm 0.01$ & $23.8 \pm 0.7$ & $0.17 \pm 0.01$ \\
\hline $\mathrm{MPP}^{+} \mathrm{I}$ in young rats & 8 & $28.5 \pm 0.8^{a}$ & $0.18 \pm 0.01$ & $22.9 \pm 0.6$ & $0.18 \pm 0.01$ \\
\hline
\end{tabular}

${ }^{a} \mathbf{P}<0.05$ in comparison with the control group, Mann-Whitney U-test. Values are means \pm S.E.

temic administration of apomorphine induced contraversive circling in these rats (see fig 1 ).

In old rats the number $\left(B_{\max }\right)$ of $D-2$ receptors, identified by specific $\left[{ }^{3} \mathrm{H}\right]$ spiperone binding, in the striatum of the injected hemisphere was higher after the MPTP injection than after the saline injection (see table 1). In young rats there were no differences between the number of D-2 receptors in the experimental and control animals. The number of D-2 receptors in the striatum of the injected hemisphere increased after the $\mathrm{MPP}^{+} \mathrm{I}$ injections in comparison with the number after the Nal injections. Increased D-2 receptor numbers were confined to the injected hemisphere; there were no differences between the number of D-2 receptors in the contralateral striata of the experimental and control groups (see table 1). Changes in receptor affinity $\left(\mathbf{K}_{\mathbf{d}}\right)$ were not observed (see table 1).

\section{Discussion}

Unilateral lesions within the nigrostriatal dopaminergic system of the rat induce circling behaviour which is thought to reflect an imbalance of dopaminergic activity in the striata. The rat rotates towards the side of the lesion, i.e. away from the hemisphere with the higher striatal dopaminergic activity. Behavioural supersensitivity is manifested by the animal rotating in a direction contralateral to the side of the lesion after the systemic administration of dopamine agonists, and appears to be due to supersensitivity of the denervated striatal dopamine receptors (Ungerstedt, 1971; Creese et al., 1977).

MPTP appears to have only a short-lasting depressive effect on nigral dopaminergic neurones in young rats since the unilateral injection of MPTP into the SNC induced ipsiversive circling for only a short period. In contrast, $\mathrm{MPP}^{+}$caused ipsiversive circling for at least 7 days as well as behavioural supersensitivity and striatal D-2 receptor supersensitivity as measured by increased $\left[{ }^{3} \mathrm{H}\right]$ spiperone binding. These behavioural results reflect biochemical alterations following the intranigral administration of MPTP and $\mathrm{MPP}^{+}$to the rat. There is no loss of striatal dopamine or its metabolites after an infusion of MPTP whereas $\mathrm{MPP}^{+}$markedly reduces striatal dopamine levels (Bradbury et al., 1986; Sun et al., 1988).

In this study apomorphine-induced contraversive circling in young rats treated with $\mathrm{MPP}^{+}$ and old rats treated with MPTP was limited compared to the high number of rotations observed following the administration of apomorphine to rats with unilateral 6-hydroxydopamine lesions (e.g. Ungerstedt, 1971; Creese et al., 1977). A possible explanation for this difference is the ratio between the number of striatal dopamine receptors in the injected and intact hemispheres. Creese et al. (1977) showed that behavioural supersensitivity increased concomitantly with receptor su- 
persensitivity. These authors described a mean increase in $\left[{ }^{3} \mathrm{H}\right]$ haloperidol binding of $50 \%$ in the striatum on the side of the 6-hydroxydopamine lesion compared with the contralateral, non-lesioned side. In contrast, the results of the present study showed that $\left[{ }^{3} \mathrm{H}\right]$ spiperone binding in the striatum on the side of the MPTP or MPP ${ }^{+}$lesion increased by only about $25 \%$ (see table 1 ).

Other authors have observed apomorphine-induced ipsilateral circling after unilateral nigral $\mathrm{MPP}^{+}$lesions (Sun et al., 1988). This is possibly the result of destruction of not only the dopaminergic neurones in the pars compacta but also non-dopaminergic neurones in the pars reticulata of the substantia nigra, since the MPP ${ }^{+}$doses used by Sun et al. (1988) were higher than those used in the present study. It has been shown that apomorphine causes ipsilateral rather than contralateral circling in rats after a non-specific unilateral lesion of the substantia nigra (Costall et al., 1976). Altar et al. (1986) reported that there was no contralateral circling in response to dopamine agonists when nigrostriatal projections had been destroyed by MPP ${ }^{+}$injections into the medial forebrain bundle in the rat although the dopamine concentrations in the ipsilateral striatum were decreased by $95 \%$. These results can be explained by the finding that high doses of $\mathrm{MPP}^{+}$ destroy GABAergic striato-nigral fibres (Altar et al., 1986). In rats with supersensitive striatal dopamine receptors following a unilateral dopaminergic lesion, circling behaviour to apomorphine is blocked by a lesion of the descending GABAergic pathway (Marshall and Ungerstedt, 1977).

Ipsiversive circling was observed in old rats for at least one week after the unilateral injection of MPTP and the systemic administration of apomorphine induced contraversive circling; the number of D-2 receptors was increased in the striatum of the lesioned hemisphere. These results suggest that the neurotoxicity of MPTP is age-dependent in the rat. MPTP has toxic effects in the nigrostriatal dopaminergic system of old rats and induces receptor supersensitivity in the denervated striatum. Previous attempts to induce lasting changes with MPTP in the rat may have been unsuccessful because young animals were used.
Other studies have also provided evidence that the effects of MPTP increase with age. Jarvis and Wagner (1985) showed that neonatal rats were resistant to the dopamine-depleting effects of MPTP whereas the toxin produced a $65 \%$ depletion of striatal dopamine in young adult rats. The enhanced toxicity of MPTP in older animals can be a toxicodynamic or toxocokinetic effect. In the former case nigrostriatal neurones of older animals may be more sensitive to the effects of MPTP, in the latter case greater quantities of MPTP or its metabolite $\mathrm{MPP}^{+}$may reach the target area. Differences between the striatal dopamine depletion induced by intracerebroventricularly administered $\mathrm{MPP}^{+}$have not been observed in old and young mice (Irwin et al., 1988), suggesting that old nigrostriatal neurones are not more sensitive to $\mathrm{MPP}^{+}$and that higher concentrations of the toxin account for the age-related effects. A possible explanation for the age dependence of MPTP toxicity is the increase of MAO B activity in the brain with age. The neurotoxic effects of MPTP have been shown to be dependent on its conversion to $\mathrm{MPP}^{+}$by MAO B (see Langston, 1987). In the rat, central MAO B activity increases over at least the first 2 years of life (Benedetti and Keane, 1980). In the mouse, striatal $\mathrm{MPP}^{+}$concentrations increase with the age of the animals injected with MPTP (Langston et al., 1987).

The present study suggests that the intranigral injection of $\mathrm{MPP}^{+}$in the rat damages the nigrostriatal dopamine system and produces D-2 receptor supersensitivity in the denervated striatum. The neurotoxic effects of MPTP appear to be age-dependent in the rat. The results suggest that, in old rats, MPTP destroys dopaminergic neurones in the substantia nigra and induces receptor supersensitivity in the striatum whereas it has only a short-lasting depressive effect on nigral dopaminergic neurones in young rats.

\section{Acknowledgements}

This study was supported by the Deutsche Forschungsgemeinschaft. The author thanks Professor K.T. Kalveram for his help. 


\section{References}

Altar, C.A., R.E. Heikkila, L. Manzino and M.R. Marien, 1986, 1-Methyl-4-phenylpyridine $\left(\mathrm{MPP}^{+}\right)$: regional dopamine neuron uptake, toxicity, and novel rotational behaviour following dopamine receptor proliferation, European J. Pharmacol. 131, 199.

Benedetti, M.S. and P.E. Keane, 1980, Differential changes in monoamine oxidase $\mathrm{A}$ and $\mathrm{B}$ activity in the aging rat brain, J. Neurochem. 35, 1026.

Bradbury, A.J., B. Costall, A.M. Domeney, P. Jenner, M.E. Kelly, C.D. Marsden and R.J. Naylor, 1986, 1-Methyl-4phenylpyridine in neurotoxic to the nigrostriatal dopamine pathway, Nature 319, 56.

Chiueh, C.C., S.P. Markey, R.S. Burns, J.N. Johannessen, A. Pert and I.J. Kopin, 1984, Neurochemical and behavioral effects of systemic and intranigral administration of $\mathrm{N}$ methyl-4-phenyl-1,2,3,6-tetrahydropyridine in the rat, European J. Pharmacol. 100, 189.

Costall, B., C.D. Marsden, R.J. Naylor and C.J. Pycock, 1976, The relationship between striatal and mesolimbic dopamine dysfunction and the nature of circling response following 6-hydroxydopamine and electrolytic lesions of the ascending dopamine systems of rat brain, Brain Res. 118, 87.

Creese, I., D.R. Burt and S.H. Snyder, 1977, Dopamine receptor binding enhancement accompanies lesion-induced behavioral supersensitivity, Science 197, 596.

Gupta, M., B.K. Gupta, R. Thomas, V. Bruemmer, J.R. Sladek, Jr. and D.L. Felten, 1986, Aged mice are more sensitive to 1-methyl-4-phenyl-1,2,3,6-tetrahydropyridine treatment than young adults, Neurosci. Lett 70,326 .

Irwin, I., G.A. Ricaurte, L.E. DeLanney and J.W. Langston,
1988, The sensitivity of nigrostriatal dopamine neurons to $\mathrm{MPP}^{+}$does not increase with age, Neurosci. Lett. 87, 51.

Jarvis, M.F. and G.C. Wagner, 1985, Age dependent effects of 1-methyl-4-phenyl-1,2,5,6-tetrahydropyridine (MPTP), Neuropharmacology 24, 581.

König, J.F.R. and R.A. Klippel, 1963, The Rat Brain: A Stereotaxic Atlas of the Forebrain and Lower Parts of the Brain Stem (Williams and Wilkins, Baltimore).

Langston, J.W., 1987, MPTP: The promise of a new neurotoxin, in: Movement Disorders 2, eds. C.D. Marsden and S. Fahn (Butterworths, London) p. 73.

Langston, J.W., I. Irwin and L.E. DeLanney, 1987, The biotransformation of MPTP and disposition of $\mathrm{MPP}^{+}$: The effects of aging, Life Sci. 40, 749.

Leysen, J.E., W. Gommeren and P.M. Laduron, 1978, Spiperone; a ligand of choice for neuroleptic receptors. 1. Kinetics and characteristics of in vitro binding, Biochem. Pharmacol. 27, 307.

Marshall, J.F. and U. Ungerstedt, 1977, Striatal efferent fibers play a tole in maintaining rotational behavior in the rat, Science 198, 62.

Sun, C.J., J.N. Johannessen, W. Gessner, I. Namura, W. Singhaniyom, A. Brossi and C.C. Chiueh, 1988, Neurotoxic damage to the nigrostriatal system in rats following intranigral administration of $\mathrm{MPDP}^{+}$and $\mathrm{MPP}^{+}, \mathrm{J}$. Neural Transm. 74, 75.

Ungerstedt, U., 1971, Postsynaptic supersensitivity after 6-hydroxydopamine induced degeneration of nigro-striatal dopamine system, Acta Physiol. Scand. Suppl. 367, 69.

Welzl, H. and K.W. Lange, 1986, Unilateral intranigral injection of MPTP in the rat induces contraversive turning, European J. Pharmacol. 132, 295. 